\title{
The Epidemiological Profile of Open Globe Injuries and Prognostic Factors in a Tertiary Care Centre
}

\author{
Hui Ruan $\mathrm{Ng}^{1,2}$, Shew Fei Chee ${ }^{1}$, Khai-Siang Chai $^{1}$, Mei Fong Chong ${ }^{1}$, Mushawiahti Mustapha ${ }^{3}$ \\ 1. Ophthalmology, Hospital Raja Permaisuri Bainun, Ipoh, MYS 2. Ophthalmology, Pusat Perubatan Universiti \\ Kebangsaan Malaysia, Kuala Lumpur, MYS 3. Ophthalmology, Pusat Perubatan Universiti Kebangsaan Malaysia, Kuala \\ lumpur, MYS
}

Corresponding author: Hui Ruan Ng, huiruan.ng@gmail.com

\section{Abstract}

\section{Purpose}

To describe the epidemiology of open globe injuries and its prognostic factors from the perspectives of a tertiary care centre in northern Malaysia.

\section{Methods}

A retrospective study of open globe injuries in a period of three years between June 2017 and May 2020. Patients presenting with open globe injuries were identified and recruited from hospital census. Case records were retrieved and analysed after recruitment.

\section{Results}

A total of 114 patients with 118 open globe injuries were included in the study. Four patients had bilateral eye involvement. Men were found to have seven and a half times higher rate of ocular injuries than women. The predominant age group of ocular trauma presentation was in younger adults between the age of 21 and 30 years old. Work-related injuries account for almost half of the globe injuries (48.7\%) followed by motor vehicle accident-related, domestic accident-related, and others. The significant factors related to the visual outcome are presenting visual acuity (VA), presence of relative afferent pupillary defect (RAPD) and vitreous loss.

\section{Conclusion}

The factors related to visual outcomes in this study may aid the clinician in determining the visual prognosis of ocular injuries. Young working males were the most susceptible group to sustain penetrating ocular injuries due to their job nature. Health education and safety at workplace are essential to reduce the occurrence of ocular injuries.

Review began 06/01/2021 Review ended 06/13/2021 Published 06/22/2021

๑) Copyright 2021 $\mathrm{Ng}$ et al. This is an open access article distributed under the terms of the Creative Commons Attribution License CC-BY 4.0., which permits unrestricted use, distribution, and reproduction in any medium, provided the original author and source are credited.
Categories: Ophthalmology, Trauma

Keywords: open globe injuries, penetrating ocular injuries, epidemiology, prognostic factor, visual outcome

\section{Introduction}

Ocular trauma is an important cause of preventable blindness worldwide. The World Health Organisation estimated that each year there is an estimated 55 million eye trauma cases that lead to restricted activities for more than one day a year, approximately 1.6 million cases of binocular blindness, 2.3 million people with bilateral low vision and almost 19 million with monocular blindness [1]. The large number of ocular trauma have placed great emphasis and challenge in the ophthalmology world on the successful repair of open globe injury and subsequent visual rehabilitation. Counselling and prognostication become an integral part of managing ocular trauma prior and after surgical repair of open globe injuries. The predictive factors for visual outcome after open globe injuries include pre-operative visual acuity (VA), relative afferent pupillary defect (RAPD), size and location of wound, uveal or vitreous prolapse, lens damage, hyphaema, presence of intraocular foreign body (IOFB) and number of surgeries done [2-5]. Based on extensive literature review, there is limited data on the epidemiology and outcome of open globe injuries in Malaysia. The latest study that was done in 2009 found that the most common cause of globe injuries were domestic accidents [6]. However, newer studies are required to help us better understand and keep updated with the current trend of globe injuries due to evolving changes. In this study, we aim to describe the epidemiology and risk factors affecting the final visual outcome of open globe injuries in our population.

\section{Materials And Methods}

This is a retrospective study from June 2017 to May 2020. We analysed the case records of patients who 
underwent surgical repair for open globe injuries within a period of three years at a tertiary referral eye care centre in Ipoh which is one of the main cities in the northern part of Malaysia. The centre receives a high volume of ophthalmic patients out of which a proportion of them presents with ocular trauma and open globe injuries. Cases were identified from the computerised admissions census. Cases with a minimum postoperative follow-up of three months, and those who had complete data about their initial and postoperative ophthalmologic examinations were included in the study. Permission to conduct the study was obtained from the local ethics committee. This research adhered to the Tenets of the Declaration of Helsinki.

Case records of 118 eyes from 114 patients with open globe injuries were reviewed. Classification for open globe injuries was based on the Birmingham Eye Trauma Terminology (BETT) [7]. The factors studied were demographic data, aetiology of injury, presenting visual acuity after injury, presence or absence of RAPD, mechanism of injury, and other associated ocular injuries as well as complications that arise from the injury.

For statistical analysis, the pre-operative VA and post-operative VA were grouped into two categories: $\leqslant 6 / 60$ and $>6 / 60$. The relationship between different preoperative variables and the final VA was analysed by Statistical Package for the Social Sciences (SPSS) version 25.0 (IBM Corp., Armonk, NY) using correlation analysis for univariate analysis. Furthermore, binary logistic regression was performed for the purpose of multivariate analysis. The association between risk factors and final VA was considered statistically significant if $\mathrm{P} \leqslant 0.05$.

\section{Results}

A total of 114 patients with 118 open globe injuries were included in the study. Four patients had bilateral eye involvement. Men ( $n=104,88.1 \%)$ were found to have seven and a half times higher rate of open globe injuries than women $(n=14,11.9 \%)$. The predominant age group of ocular trauma presentation was in younger adults between the age of 21 and 30 years old. Most of the ocular injuries in this study has a propensity to involve the left eye $(n=70,59.3 \%)$. Out of the 118 globe injuries, slightly more than half of the cases were of Malay ethnicity $(n=65,55.1 \%)$, followed by Indians $(n=20,16.9 \%)$, Chinese $(n=16$, $13.6 \%)$, and others $(n=17,14.4 \%)$ owing to the fact that the Malays constitute the largest ethnic group in Malaysia. The category of others involved foreigners from Indonesia, Bangladesh, and India. The majority of the patients ( $n=108,91.6 \%$ ) presented to the hospital within 24 hours of trauma. Unfortunately, there were five patients who presented one day later and another five presented two days after trauma. The mean follow-up duration for these patients were 4.7 (+/-1.8) months. Approximately one-third of the cases had initial presenting VA of counting fingers or worse $(n=45,38.1 \%), 52(44.1 \%)$ cases with VA of $6 / 24$ to $6 / 60,10$ (8.5\%) cases with VA of 6/12 to 6/18, and 11 (9.3\%) cases with VA of 6/9 or better. At three months post-operative follow-up, the number of eyes with VA 6/9 or better improved to $22.9 \%(n=27), 12$ (10.1\%) eyes had VA of 6/12 to 6/18, 29 (24.6\%) eyes had VA of 6/24 to 6/60, and 50 (42.4\%) eyes had VA of counting fingers and worse. Eighty-one (68.6\%) eyes required a single surgery, while 34 (28.8\%) eyes required two surgeries and the remaining three (2.5\%) required three surgeries.

Work-related injury was the most common cause of penetrating ocular injuries, accounting for 54 (45.7\%) cases, followed by motor vehicle accident-related $(n=33,27.9 \%)$, domestic accident-related $(n=$ $28,23.7 \%)$, and others ( $n=3,2.5 \%$ ) which includes sports-related and assault-related injuries (Figure 1). For work-related injuries, the factory was the most common setting for ocular trauma (Figure 2), followed by agriculture, automotive and technical. Among domestic accident-related injuries, half of them $(\mathrm{n}=14$, $50.0 \%)$ occurred while playing, followed by household activities ( $n=7,25.0 \%)$ and falls $(n=5,17.9 \%)$, while the remainder were sustained in various ways. Playing activities include dealing with fire crackers during the festive seasons, handling toy guns and unsupervised usage of potentially sharp objects like clothes hanger. 


\section{Cureus}

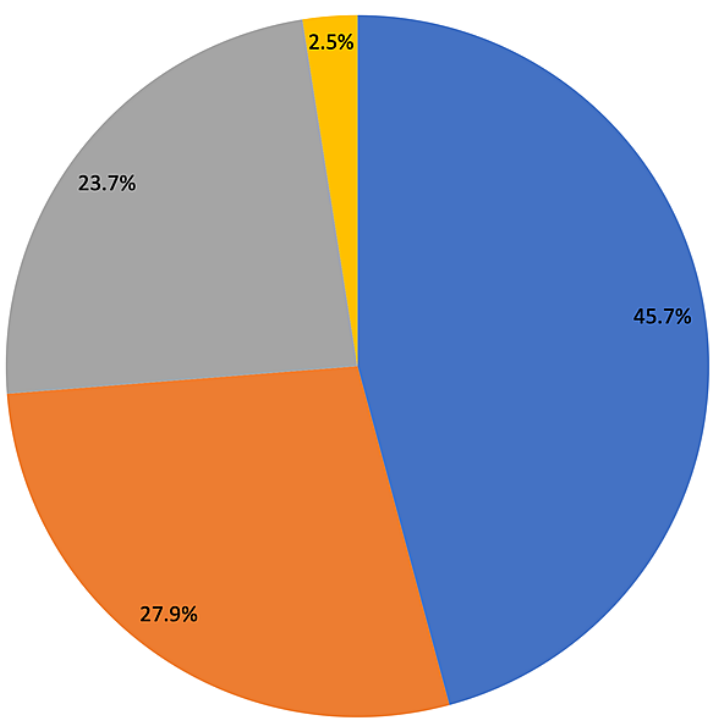

a Work

a MVA

nomestic

Others

FIGURE 1: Distribution in percentages of penetrating ocular injuries $(n=$ 118) by setting.

MVA: motor vehicle accident.

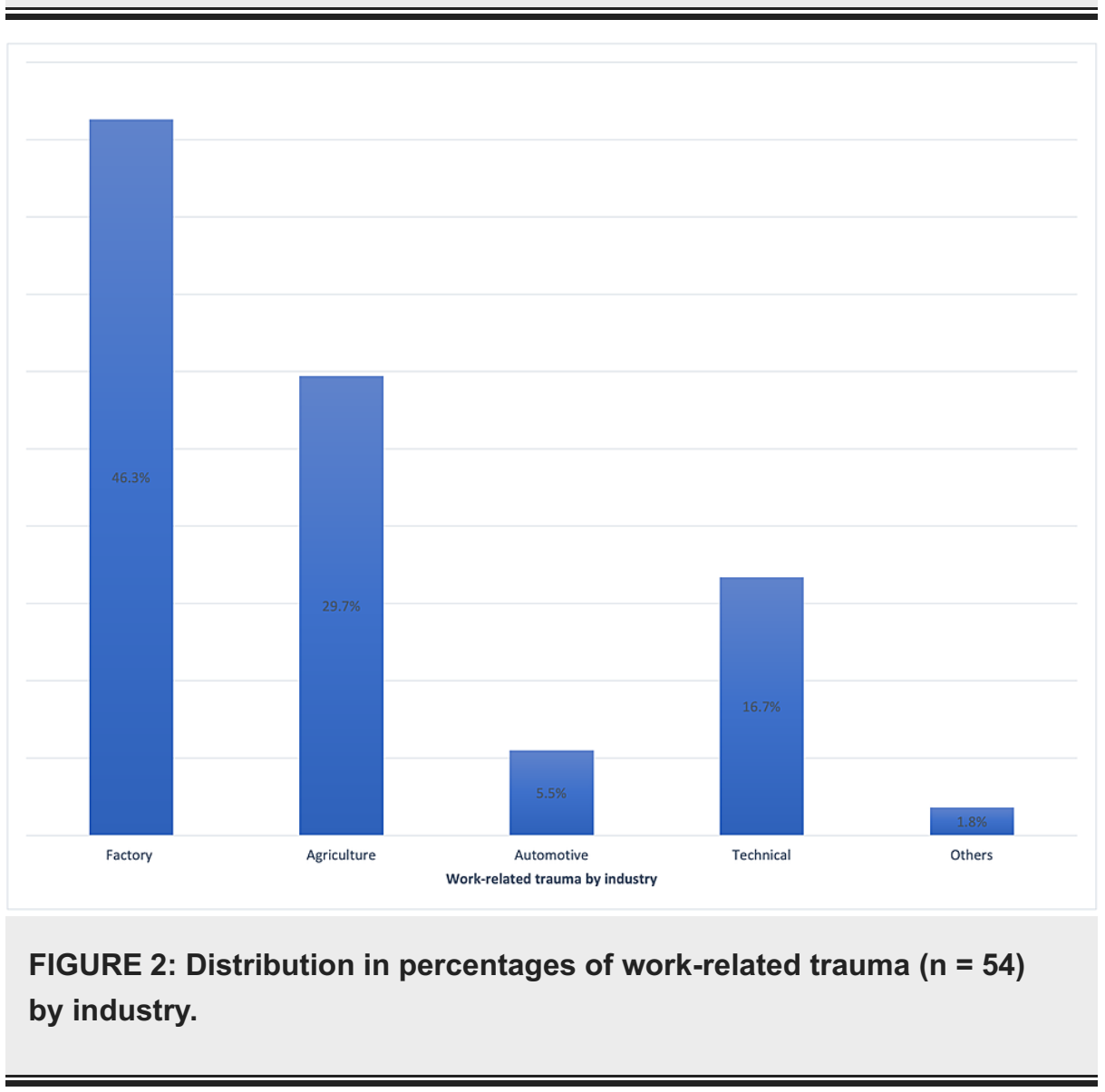

Lid laceration was an accompanying injury in 16 (13.6\%) eyes. RAPD was present in almost half of the cases $(n=58,49.1 \%)$. Hyphaema was noted in 42 (35.6\%) eyes. Lens was found to be cataractous with or without anterior capsular rupture in 43 eyes (36.4\%). Half of the eyes had vitreous loss ( $\mathrm{n}=62,52.5 \%)$ while intraocular foreign body was seen in 27 (22.9\%) eyes. 


\section{Cureus}

The preoperative variables that were statistically significant for predicting final visual outcome at three months post-operatively include initial presenting VA, presence of RAPD, eyelid laceration involvement, and vitreous loss based on the univariate logistic regression analysis (Table 1). All the significant variables in univariate analysis were added in the multivariate analysis using binary logistic regression to further analyse their associations with final vision outcome. Based on Table 2, the most statistically significant factors leading to poor visual outcome on multivariate logistic regression analysis are presenting VA, presence of RAPD and vitreous loss.

\begin{tabular}{|c|c|c|c|c|}
\hline & Odds ratıo & P-value & CV & $95 \% \mathrm{Cl}$ tor CV \\
\hline Inıtıal VA & -2.126 & 0.000 & 0.065 & $0.024-0.1 / 7$ \\
\hline RAPD & 3.855 & 0.000 & 47.218 & $15.311-45.621$ \\
\hline Eyelid involvement & 1.366 & 0.029 & 4.333 & $1.165-16.125$ \\
\hline Cataract & 0.398 & 0.305 & 1.489 & $0.696-3.186$ \\
\hline Hyphaema & 0.961 & 0.018 & 2.613 & $1.181-5.785$ \\
\hline Vitreous loss & 3.182 & 0.000 & 24.091 & $9.166-63.321$ \\
\hline IOFB & 0.671 & 0.144 & 1.957 & $0.796-4.810$ \\
\hline
\end{tabular}

TABLE 1: Univariate logistic regression: pre-operative variables affecting final VA with statistical calculations.

RAPD: relative afferent papillary defect; IOFB: intraocular foreign body; CV: coefficient of variation; CI: confidence interval; VA: visual acuity.

\begin{tabular}{|c|c|c|c|c|}
\hline & Odds ratio & P-value & CV & $95 \% \mathrm{Cl}$ for $\mathrm{CV}$ \\
\hline Initial VA & 2.045 & 0.004 & 0.129 & $0.032-0.528$ \\
\hline RAPD & 2.833 & 0.000 & 16.996 & 4.229-33.305 \\
\hline Eyelid involvement & -0.991 & 0.297 & 0.371 & $0.058-2.391$ \\
\hline Vitreous loss & 1.263 & 0.051 & 3.535 & $0.900-13.893$ \\
\hline
\end{tabular}

TABLE 2: Multivariate logistic regression: pre-operative variables affecting final VA with statistical calculations.

RAPD: relative afferent pupillary defect; CV: coefficient of variation; Cl: confidence interval; VA: visual acuity.

\section{Discussion}

In most population-based studies, there is a strong tendency for open globe injuries to involve male [2-5,815]. Similarly in this study, male was the predominant gender. This reflects the predominant involvement of men in higher-risk activities namely work or sports-related activities and motor vehicle accidents. The majority of patients were in the younger age group (less than 40 years old) which is also similar to other studies till date [2-4].

In this study, poor presenting visual acuity is significantly associated with poor post-operative visual outcomes. This is in accordance with other studies that showed presenting VA is the most important prognostic factor in determining visual outcome [2-5]. Presence of RAPD and vitreous loss were statistically significant to predict post-operative visual outcomes in this study. The final visual outcome was worse if there was the presence of RAPD as seen in other studies [2-5]. Presence of vitreous loss was reported to be associated with poor visual outcome $[8,13-15]$. The postulation was due to the possible vitreoretinal traction which may potentially lead to retinal detachment [2-3].

Work-related eye injuries were the most common cause of penetrating eye injury, accounting for almost half of the cases. This is in accordance with other reported studies from both developed and developing nations $[8,13-15]$. In the past, domestic accident-related injuries were the most common cause of open globe 
injuries in Malaysia. The most common setting for work-related injuries in this study was in factories followed by agricultural and technical-related fields. As work-related injuries account for the highest proportion of penetrating ocular injuries, it is very important to highlight the need for the higher authorities to intervene and help to take preventive measures. This includes the education and enforcement of the usage of personal protective equipment (PPE) at workplace to prevent ocular injuries. Besides medical consequences of loss of vision, work-related eye injuries are associated with socioeconomic burden, which includes the cost of medical care, time off work, loss of income, and permanent disability. As patients' hospital bills are heavily subsidised by the government in Malaysia, this also poses a financial burden to the government. Therefore, taking preventive measures such as reinforcing the law for mandatory PPE usage at workplace is one of the best approaches to be considered by the legislative council.

This research is however limited by the lack of data on the detail of personal protective equipment (PPE) usage during work, due to the retrospective nature of this study. A prospective study in the future would be able to gather more meaningful data.

\section{Conclusions}

Factors that determine the visual outcome of penetrating ocular injuries include pre-operative VA, presence of RAPD and vitreous loss. These factors may aid the clinician in determining the prognosis of ocular injuries. Young working males were the most susceptible group to sustain penetrating ocular injuries due to their job nature. Promotion of health education and safety at workplace are therefore essential to reduce the occurrence of ocular injuries.

\section{Additional Information \\ Disclosures}

Human subjects: Consent was obtained or waived by all participants in this study. Medical Research and Ethics Committee (MREC) Malaysia issued approval NMRR-20-2010-55770. We have obtained the approval for the conduct of study titled 'The Epidemiological Profile of Open Globe Injuries and Prognostic Factors in a Tertiary Care Centre' from Medical Research and Ethics Committee (MREC) Malaysia on 2nd November 2020. Animal subjects: All authors have confirmed that this study did not involve animal subjects or tissue. Conflicts of interest: In compliance with the ICMJE uniform disclosure form, all authors declare the following: Payment/services info: All authors have declared that no financial support was received from any organization for the submitted work. Financial relationships: All authors have declared that they have no financial relationships at present or within the previous three years with any organizations that might have an interest in the submitted work. Other relationships: All authors have declared that there are no other relationships or activities that could appear to have influenced the submitted work.

\section{Acknowledgements}

We would like to thank the Director-General of Health, Malaysia for his permission to publish this article.

\section{References}

1. Négrel AD, Thylefors B: The global impact of eye injuries . Ophthalmic Epidemiol. 1998, 5:143-69. 10.1076/opep.5.3.143.8364

2. Agrawal R, Rao G, Naigaonkar R, Ou X, Desai S: Prognostic factors for vision outcome after surgical repair of open globe injuries. Indian J Ophthalmol. 2011, 59:465-70. 10.4103/0301-4738.86314

3. Agrawal R, Wei HS, Teoh S: Prognostic factors for open globe injuries and correlation of ocular trauma score at a tertiary referral eye care centre in Singapore. Indian J Ophthalmol. 2013, 61:502-6. 10.4103/03014738.119436

4. Ozturk T, Cetin Dora G, Ayhan Z, Kaya M, Arikan G, Yaman A: Etiology and visual prognosis in open globe injuries: results of a tertiary referral center in Turkey. Sci Rep. 2019, 9:17977. 10.1038/s41598-019-54598-W

5. Cruvinel Isaac DL, Ghanem VC, Nascimento MA, Torigoe M, Kara-José N: Prognostic factors in open globe injuries. Ophthalmologica. 2003, 217:431-5. 10.1159/000073075

6. Madhusudhan AP, Evelyn-Tai LM, Zamri N, Adil H, Wan-Hazabbah WH: Open globe injury in Hospital Universiti Sains Malaysia - a 10-year review. Int J Ophthalmol. 2014, 7:486-90. 10.3980/j.issn.22223959.2014.03.18

7. Kuhn F, Morris R, Witherspoon C, Mester V: The Birmingham Eye Trauma Terminology system (BETT). J Fr Ophtalmol. 2004, 27:206-10. 10.1016/s0181-5512(04)96122-0

8. Loon SC, Tay WT, Saw SM, Wang JJ, Wong TY: Prevalence and risk factors of ocular trauma in an urban south-east Asian population: the Singapore Malay Eye Study. Clin Exp Ophthalmol. 2009, 37:362-7. 10.1111/j.1442-9071.2009.02035.x

9. Mallika P, Tan A, Asok T, Faisal H, Aziz S, Intan G: Pattern of ocular trauma in Kuching, Malaysia . Malays Fam Physician. 2008, 3:140-5.

10. Yong GY, Pan SW, Humayun Akhter F, Law TN, Toh TH: Determinant factors of poor visual outcome after ocular trauma: a retrospective study in Central Sarawak, Malaysia. Asia Pac J Ophthalmol. 2016, 5:137-42. 10.1097/APO.0000000000000150

11. Mansouri M, Faghihi H, Hajizadeh F, et al.: Epidemiology of open-globe injuries in Iran: analysis of 2,340 cases in 5 years (report no. 1). Retina. 2009, 29:1141-9. 10.1097/IAE.0b013e3181a395ac

12. Hooi SH, Hooi ST: Open-globe injuries: the experience at Hospital Sultanah Aminah, Johor Bahru . Med J 


\section{Cureus}

Malaysia. 2003, 58:405-12

13. Wong TY, Lincoln A, Tielsch JM, Baker SP: The epidemiology of ocular injury in a major US automobile corporation. Eye. 1998, 12:870-4. 10.1038/eye.1998.220

14. Wang W, Zhou Y, Zeng J, Shi M, Chen B: Epidemiology and clinical characteristics of patients hospitalized for ocular trauma in South-Central China. Acta Ophthalmol. 2017, 95:e503-10. 10.1111/aos.13438

15. Voon LW, See J, Wong TY: The epidemiology of ocular trauma in Singapore: perspective from the emergency service of a large tertiary hospital. Eye. 2001, 15:75-81. 10.1038/eye.2001.18 